\title{
Influencing Factors and Development of Logistics Service Outsourcing of Industrial Enterprises
}

\author{
Rui Wang \\ Xi`an International University, Xi`an, Shaanxi, 710077, China
}

Keywords: industrial enterprise; logistics service outsourcing; influencing factor; development

\begin{abstract}
In the practical development process of industrial enterprises, logistics service outsourcing receives extensive attention. But in the practical development process, some influencing factors often occur and seriously affect logistics service outsourcing of industrial enterprises. Thus, in the practical development process, it is necessary to summarize rich experience, use scientific and reasonable methods for service innovation, establish correct concept, increase entire management force and lay a solid foundation for follow-up development.
\end{abstract}

\section{Introduction}

In the development process of logistics service outsourcing of industrial enterprises, many influencing factors appear. It is required to carry out scientific and reasonable analysis, use concentrated core business, specify superior resources of enterprises, promote competitive capacity and reach the expected objective.

\section{Analysis of Research Content}

With the development of national economy, economic integration mode has received extensive attention. Division of labor in society starts to develop to refinement. Enterprises have intensively developed superior resources to the ore business, and concentrated non-core business and the business without competitive edge for outsourcing. Such high-end orientation can meet current logistics outsourcing development demand. In the production and service process of industrial enterprises, outsourcing can expand production scale, verify outsourcing services and form favorable competitive mechanism and mode. Since 1999, Chinese industrial enterprises have improved the contribution rate (about 60\%). It thus can be seen that, industrial enterprises can increase national GDP value and promote competitiveness improvement. Although China's industrial economic level improves, a series of problems also occur in the practical development process, such as environmental pollution, energy consumption, labor production, independent innovation ability and profit rate. These problems seriously affect the development of industrial economy, and industrial economy cannot meet current development demand. In the aspect of logistics service outsourcing, industrial enterprises can reform traditional strategic pattern, relieve current problems, facilitate core competitiveness improvement, promote enterprises to concentrate competitiveness business, increase added value of products and satisfy current development demand.

\section{Influencing Factors of Logistics Service Outsourcing of Industrial Enterprises}

Logistics service outsourcing of industrial enterprises should be classified from various types. Internal and external factors should be specified. Internal influencing factors include external service concept, logistics strategic mechanism and mode. External influencing factors include development level and service ability of logistics industry. Scientific and reasonable analysis and research should be conducted. Comprehensive analysis method should be applied to formulate the thorough control plan. In the scientific analysis and research, a reasonable way should be applied for control mechanism and system innovation. Under the condition of detailed analysis, it is required to promote 
quantitative research of resources and improve entire working quality. The specific influencing factors are as follows:

\subsection{Influencing factors of logistics outsourcing concept}

In the practical development period of industrial enterprises, logistics outsourcing concept has direct influence on the success of logistics outsourcing. It belongs to a complex system and concerns business reengineering ability and staff mobilization effect of enterprises. Rights and liabilities should be analyzed and studied to understand whether staff interest is affected. Under the condition where industrial enterprises lack correct logistics outsourcing concept, logistics service outsourcing will be affected. If there is no strict analysis and investigation, the long-term development of the entire work will be affected. For industrial enterprises, if the high-level leaders fail to establish correct concept of logistics service outsourcing, scientificity and rationality of strategic content will be influenced, and strict methods cannot be used to manage logistics service outsourcing. This will affect working effect of each aspect. Therefore, industrial enterprises should carry out analysis scientifically and apply rational methods for control and coordination. Under the situation of mutual restriction, industrial enterprises should conduct handling and control in a rational manner.

\subsection{Influencing factors of logistics decision handling}

For industrial enterprises, logistics strategy is important. Without scientific and reasonable decisions, logistics service outsourcing will be affected. On the one hand, enterprises fail to conduct scientific and reasonable researches on the strategy and fail to establish rational strategic decision-making mechanism. When logistics strategy level of the enterprises is high, the entire competitive edge can improve. But, in the logistics handling process of industrial enterprises, many enterprises fail to use scientific and reasonable ways to enhance decision-making effect, and lack scientific research modes and methods. On the other hand, there is no rational resource management during logistics service outsourcing, and resource waste often occurs. Scientific methods should be applied to promote the possibility of logistics service outsourcing. Under mutual researches, if enterprises' logistics handling ability is low, serious problems will happen to the development of logistics service outsourcing, and it is hard to improve working effect. Thus, logistics service decisions of industrial enterprises will generate certain influence on outsourcing development. It is necessary to conduct scientific and reasonable researches, establish modern working system, enhance management effect and reach the expected objective.

\subsection{Influencing factors of logistics industry development}

In the development process of regional logistics enterprises, the development level will generate certain influence on outsourcing enthusiasm of industrial enterprises. If regional logistics development level is low, and the number of logistics enterprises is very small, industrial enterprise will investigate the logistics enterprises with a low scale, and service outsourcing cannot be conducted better. If the logistics industry development level in the region is high, industrial enterprises can actively outsource logistics services and take active part in various activities. Hence, the high economic level will form. This can promote rational implementation and development of logistics service outsourcing and facilitate favorable development of work in all aspects.

\subsection{Influencing factors of service capability of logistics enterprises}

Service capability of logistics enterprises will influence logistics service outsourcing of industrial enterprises. It is one of important influencing factors. If service capability of logistics enterprises is low, they may be refused by industrial enterprises. If service capability of logistics enterprises is high, they can gain the support of industrial enterprises. Thus, in the development process of logistics enterprises, their resource capability and level will influence logistics service outsourcing of industrial enterprises. Scientific and rational researches should be conducted. Under the condition of comprehensive analysis, superior resources should be studied and explored. The operation management features should be specified and researched rationally and scientifically. 


\section{Quantitative Analysis on Influencing Factors of Logistics Service Outsourcing of Industrial Enterprises}

For industrial enterprises, the influencing factors of logistics service outsourcing have six sub-factors which are correlative and independent. In the practical analysis process, the questionnaire survey can be used to gain more data information so as to understand the influencing factors of logistics service outsourcing of industrial enterprises. In the questionnaire design process, seven quantitative analysis methods were used for exploration. Under the condition of measuring service degree, scientific methods can be used for analysis. 1 completely agree, 2 not agree, 3 disagree a little, 4 not matter, 5 agree a little, 6 agree, 7 completely disagree. Based on analysis of influence of various factors, superior resources and various influencing factors should be rationally analyzed to know all kinds of problems. Meanwhile, the working force should increase. In addition, after questionnaire survey, production and procurement development should be carried out for industrial enterprises. In the marketing link, business outsourcing should be specified. Based on scientific analysis, it is required to clearly know whether problems exist in logistics service outsourcing, and rational measures should be taken to solve the problems so as to overall improve working efficiency and quality. In each region of China, industrial enterprises have started to study logistics service outsourcing, apply rational methods for reform and understand practical conditions of enterprise development.

For industrial enterprises, it is required to specify whether there are influencing factors in logistics service development process in order to achieve the objective of service outsourcing. Under the condition of characteristic value research, rational methods should be applied to measure logistics service outsourcing of industrial enterprises. After knowing the development capacity and service capacity of the industry, the analysis and research force should be enhanced to improve working effect. However, correlation analysis easts in the analysis of logistics service outsourcing by using various factors. Under the situation of mutual service, various concepts should be specified. And, analysis and exploration should be based on scientific researches.

\section{Development of Logistics Service Outsourcing of Industrial Enterprises}

In the development process of logistics service outsourcing of industrial enterprises, various influencing factors should be investigated to clearly know outsourcing concept factors and industry development level. In the research process, rationale analysis should be conducted for all kinds of influencing factors to specific correlation features. The research should be made from logistics decision making and service level. The research and discussion should be made according to current working features to improve working effect.

\subsection{To formulate thorough decision scheme}

In the process of logistics service outsourcing, industrial enterprises need to formulate thorough decision schemes, know influencing factors and practical conditions, reform decision schemes based on scientific research and improve working effect. On the one hand, before making decisions, industrial enterprises should analyze market conditions, clearly know the influence in the market, improve decision content and mechanism based on all-round analysis of market factors and rationally carry out market factors. On the other hand, decision content should innovate. Based on improving decision content accuracy and rationality, scientific methods should be used to improve decision content innovation. During decision making, thorough working mechanism should be formulated. Besides, logistics service outsourcing features and practical content of enterprises should be combined for comprehensive research to improve working level. 


\subsection{To establish correct concept}

In the process of logistics service outsourcing management, industrial enterprises need to establish correct concept, specify the features and concrete content of service concept, use scientific and reasonable methods to carry out detailed research and improve working effect under the condition of promoting outsourcing concept correctness. Firstly, rational innovation should be conducted for outsourcing concept, and thorough work program should be formulated. Under the support of advanced concept, work reliability and effectiveness should improve. For logistics service outsourcing concept, it is necessary to combine economic development features and conditions for scientific concept analysis and innovation to promote accuracy and reliability of logistics service outsourcing concept. Secondly, in service concept innovating process, it is required to establish correct working concept, establish rational outsourcing work system, innovate for and reform service outsourcing concept under the condition of mutual coordination and promote outsourcing working effect based on following modern working principles. Finally, in the logistics service outsourcing development process, industrial enterprises should complete current working task through advanced concept, and apply rational working methods to carry out research in daily work to overall promote the efficiency and quality of logistics service outsourcing and improve logistics service outsourcing quality.

\subsection{To choose suitable logistics service enterprises}

In the development process, industrial enterprises should overall analyze influencing factors of logistics service outsourcing, choose suitable logistics service enterprises, formulate thorough work system and mode, apply rational methods for management, enhance work force and promote working quality of logistics service enterprises. First of all, during choosing logistics service enterprises, it is required to analyzer and study enterprises' work, promote logistics service outsourcing effect and better complete the tasks under the condition of enhancing management effect. Secondly, during choosing logistics service enterprises, industrial enterprises should conduct rational management and control, find out the problems timely, take rational measures to solve problems, and improve service quality based on working mode innovation. Finally, the logistics service enterprises with high resource quality and high core competitiveness should be chosen in service work. Rational outsourcing treatment should be conducted for logistics service. Under the condition of mutual coordination, reasonable management should be carried out to improve working effect.

\subsection{To optimize service mode and mechanism}

In the process of logistics service outsourcing, industrial enterprises should overall optimize service mode and mechanism, formulate thorough management system, innovate for service work mode and promote working effect. On the one hand, reasonable survey should be made in service mode optimization process to understand logistics service outsourcing features. And, scientific management method should be adopted. Based on detailed research, advanced logistics service mode should be applied to enhance outsourcing quality and meet current work requirements. On the other hand, a favorable work system can form in management work to increase logistics service force. Besides, advanced work mode can innovate. Traditional working method should be reformed. Based on improving logistics service outsourcing quality, working mechanism should be optimized. In the meantime, differential management should be applied to coordinate the relations of various aspects. Under the condition of scientific exploration, logistics service outsourcing effect should improve.

\section{Summary}

In the practical development process, industrial enterprises should pay attention to influencing factors of logistics service outsourcing. Based on scientific analysis, reasonable manners should be applied for management work, and appropriate logistics service enterprises should be chosen for outsourcing. Besides, thorough management plan and coordination mechanism should be formulated 
to promote job quality and level and optimize management system.

\section{References}

[1] Zhou Rongyi, Zhao Hansheng, Xu Liping. Study on Tobacco Production and Marketing Process Reengineering under Tobacco Farmers Cooperative, Commercial Accounting, 2016(16):22-25.

[2] Wang Wei, Thought of Financial System of B2C-based Supply Chain - Case Study of Delta, Chinese \& Foreign Entrepreneurs, 2017(16):34-36.

[3] Huo Ying, Huo Jingang, Matched Emerging Industry Development Countermeasures for Production service Industry in Heilongjiang, 2017(3):132-136.

[4] Wang Xuyang, Simulation Study on Automobile Parts Inventory Management in Supply Chain Environment, Anhui University of Science and Technology, 2017.

[5] Sui Jiatong, Research on Interactive Development Relation between Production-based Service Industry and Manufacturing Industry in Shandong Province, Shandong University, 2016. 